\title{
Microstructure and Mechanical Behavior of High-Entropy Alloys
}

\author{
Joseph J. Licavoli, Michael C. Gao, John S. Sears, Paul D. Jablonski, and Jeffrey A. Hawk
}

(Submitted August 6, 2015; published online August 27, 2015)

\begin{abstract}
High-entropy alloys (HEAs) have generated interest in recent years due to their unique positioning within the alloy world. By incorporating a number of elements in high proportion, usually of equal atomic percent, they have high configurational entropy, and thus, they hold the promise of interesting and useful properties such as enhanced strength and alloy stability. The present study investigates the mechanical behavior, fracture characteristics, and microstructure of two single-phase FCC HEAs CoCrFeNi and CoCrFeNiMn with some detailed attention given to melting, homogenization, and thermo-mechanical processing. Ingots approaching $8 \mathrm{~kg}$ in mass were made by vacuum induction melting to avoid the extrinsic factors inherent to small-scale laboratory button samples. A computationally based homogenization heat treatment was given to both alloys in order to eliminate any solidification segregation. The alloys were then fabricated in the usual way (forging, followed by hot rolling) with typical thermo-mechanical processing parameters employed. Transmission electron microscopy was subsequently used to assess the single-phase nature of the alloys prior to mechanical testing. Tensile specimens (ASTM E8) were prepared with tensile mechanical properties obtained from room temperature through $800{ }^{\circ} \mathrm{C}$. Material from the gage section of selected tensile specimens was extracted to document room and elevated temperature deformation within the HEAs. Fracture surfaces were also examined to note fracture failure modes. The tensile behavior and selected tensile properties were compared with results in the literature for similar alloys.
\end{abstract}

Keywords deformation, FCC crystal structure, fracture, highentropy alloys, microstructure, tensile properties

\section{Introduction}

Consider the design of an entirely new alloy. The first design input is always the desired properties defined by the target application. One may then go on to choose the crystal structure (e.g., FCC, BCC, etc.) that will impart the desired properties. The alloy may also be solid solution or precipitation strengthened in which case compatible elemental additions and their effects can then be considered. For example, if a FCC solid solution strengthened alloy is the goal, per the Hume-Rothery rules, a list might be made of elements having a stable FCC matrix- $\mathrm{Al}, \mathrm{Ni}, \mathrm{Cu}$, etc., as well as a list of elements that form FCC phase at some temperature (Fe, Co, etc.). However, this list may be misleading. For example, adding $\mathrm{Al}$ (FCC) to $\mathrm{Fe}$ stabilizes the BCC phase, while adding $\mathrm{Mn}$ (BCC) to $\mathrm{Fe}$ stabilizes the FCC phase. Thus, a more sophisticated approach is required such as the well-known CALPHAD method. The successful use of this method is highly dependent on the availability of accurate thermodynamic databases and must be coupled with experimental validation.

Joseph J. Licavoli, Paul D. Jablonski, and Jeffrey A. Hawk, National Energy Technology Laboratory, Albany, OR 97321; and Michael C. Gao and John S. Sears, National Energy Technology Laboratory, Albany, OR 97321; and AECOM, National Energy Technology Laboratory, Albany, OR 97321. Contact e-mail: jeffhawk4@comcast.net.

The application of the CALPHAD method in alloy design has led to significant departures from conventional compositions; but for both practical and historical reasons, most alloys are designed around one principal element. The supposition is that the principal element's native structure will dominate the characteristics of the alloy leading to similar performance. Additional elements are then added to modify some combination of physical and/or mechanical properties relevant to the alloy's intended application. This may include phase stability, solid solution strengthening, and secondary phase formation. In this manner, classes of alloys have been developed around iron, aluminum, titanium, and nickel. While the number of commercially relevant alloys developed in this manner is large, designing an alloy around one element is restrictive. One rapidly expanding field of research is focused on designing alloys with multiple principle elements typically in equi-molar, or near equi-molar, concentrations $(\operatorname{Ref} 1,2)$. These alloys have been designated high-entropy alloys (HEAs) (Ref 3).

Generally, HEAs are materials with at least five or more principal elements, and were so named because their mixing entropies in solution are much higher than alloys based on a single element. Some alloys with $<5$ principal elements have been regarded as HEAs, though these are sometimes referred to as "medium entropy" alloys. To be considered a principal element, a concentration of between 5 and 35 at.\% is necessary (Ref 3,4). Minor elements can also be included, typically at levels $<5$ at.\%. The resultant HEA is defined by the "group" of principal elements from which it is composed rather than one single principal element as in traditional alloys. The defining characteristic of an HEA is stabilization of a high-entropy solid solution phase. This phase may either compose the entire microstructure or coexist with strengthening phases. The entropy stabilized solid solution inhibits potentially undesirable 
phases that can form when multiple elements exist together in high concentrations. More importantly, a highly disordered solid solution imparts appealing properties that are typically not observed in traditional alloys. For example, HEA properties may include high room temperature strength/hardness, good wear resistance, good high temperature strength, good structural stability, and good corrosion/oxidation resistance (Ref 1). While these properties appear promising, many studies were carried out utilizing small-scale melting techniques, and therefore, the observed properties may not translate directly upon scale up when the same compositions are produced via commercial methods.

The performance levels that may be achieved from an alloy are highly sensitive to processing history. Within the HEA literature, there have been limited investigations on the importance of melt processing, homogenization heat treatment, and thermo-mechanical processing. Kao et al. (Ref 5) studied the microstructure and mechanical properties of $\mathrm{Al}_{x} \mathrm{CoCrFeNi}$ in the as-cast, "homogenized" (so-called, since no criteria for the homogenization cycle used was given), and mechanically deformed states. Zhang et al. subsequently examined the effect of annealing on the microstructure and properties of $\mathrm{CoCrFeNiCuAl}$ (Ref 6) and $\mathrm{CoCrFeNiTiAl}_{x}$ (Ref 7). Ng et al. used a series of thermomechanical treatments to study the stability of the solid solution phases in a high-entropy $\mathrm{Al}_{0.5} \mathrm{CoCrCuFeNi}$ and found that the solid solution phases were stable only at high temperatures $>850{ }^{\circ} \mathrm{C}$ and at temperatures below $300{ }^{\circ} \mathrm{C}(\operatorname{Ref} 8)$. Most HEA studies present properties for the material in the as-cast condition. In this state, the dendritic structures that result from nonconsumable arc melting (i.e., button) dominate performance. Finally, many small-scale melts only allow for compression samples to be produced as opposed to ASTM standard size tensile specimens. The limited geometric sample size has forced comparisons between HEA compression tests and commercial alloy tensile tests which may be misrepresentative (Ref 9).

Non-consumable arc melting is useful for making smallscale trial heats of material for laboratory investigations. However, this approach has many technical issues that can potentially influence the characteristics of the resulting alloy. A close look at non-consumable arc melting is needed to understand these limitations. Consider a non-consumable arc melted ingot. Such ingots are produced in contact with a watercooled copper hearth. The hearth cools the ingot such that it is never fully molten, and as such, this melting technique makes it highly improbable, if not impossible, to fully and completely mix the elemental constituents in the alloy. Differences in density and melting point of the elements tend to exacerbate this problem with high density, high melting point elements such as $\mathrm{W}, \mathrm{Ta}$, and $\mathrm{Nb}$ being particularly hard to incorporate into a non-consumable arc melted ingot.

A solidification artifact also arises from this approach. Typically, an ingot made in this way results in an erratic dendrite structure that forms during the solidification process. If the portion of the alloy ingot in contact with the copper hearth melts, it solidifies nearly instantaneously forming a "chill grain" region which is free of dendrites. Quite often, the bottom of the ingot is not completely melted and displays characteristics of a heat-affected zone found in weldments (which is effectively what a non-consumable arc melted ingot is). Meanwhile, those regions near the upper surface, and topmost sides, solidify into long columnar dendrite grains with orientations dependent on both hearth configuration (i.e., the direction of heat extraction) and melt practice (i.e., heat input).
Furthermore, the inevitable shrink cavity is difficult to control and may, or may not, have connectivity to the surface. Thus, the structure of the ingot, and presumably the physical and mechanical properties are complex, difficult to describe, and vary throughout the ingot, as well as from ingot to ingot. As a result of these melt-solidification artifacts along with other considerations, non-consumable arc melting is not used to produce alloys on an industrial scale because they may produce non-representative and non-reproducible properties. The HEAs produced and reported herein were made by conventional vacuum induction melting (VIM), which is a commercial type process often used to produce industrial scale ingots.

The alloys investigated in this effort represent well-reported, single-phase HEAs of CoCrFeNi and CoCrFeMnNi. Previous results in the literature on similar HEAs (Ref 10-13) do not provide much information related to the effects of ingot size and thermo-mechanical processing on the chemistry, microstructure, and mechanical properties. This report focuses on NETL's efforts to produce single-phase HEAs of kilogram size using commercial melting, thermo-mechanical processing, and heat treatment practices. The results of the melting campaign are provided through analysis of microstructure and mechanical behavior at various temperatures.

\section{Experimental Procedures}

\subsection{Alloy Manufacture and Heat Treatment}

Two alloys with nominal compositions CoCrFeNi (designated as HEA1) and CoCrFeMnNi (designated as HEA2) were melted using VIM. Each VIM furnace charge weighed approximately $7.8 \mathrm{~kg}$ and was composed of feedstock of commercial high purity pressed into compacts that would fit into the crucible. Some elements were introduced loosely in the crucible as they did not compact well (e.g., Mn). Nickel and cobalt additions were melt consolidated before being alloyed with the rest of the elements. A summary of the melt practice, homogenization heat treatment, and thermo-mechanical processing will not be given here. In depth discussion can be found in Ref 14.

Each constituent was placed in the crucible such that sequential melt-in of various materials occurred. Considerations for where each element was placed included its melting temperature, form, and degree of interaction with the electromagnetic field. Sequential melt-in is critical to avoid "bridge" formation during melting and to ensure the availability of proper clearance for further additions. The heats were poured into zirconia-coated graphite molds while under an argon partial pressure of 200 torr $(0.26 \mathrm{~atm})$. The mold cavity was a $75 \mathrm{~mm}$-diameter cylinder with a funnel-shaped riser (i.e., hot top) to minimize pipe shrinkage.

After casting, the hot tops were cut from each ingot. A $2 \mathrm{~mm}$-thick slice was then taken from the top of the ingot for chemical analysis. A Rigaku ZSX Primus II x-ray fluorescence (XRF) analyzer with NIST traceable standards and reported accuracies to $0.01 \mathrm{wt} \%$ was used to carry out bulk chemical analysis. A LECO CS444LS was used to determine carbon and sulfur levels. Oxygen and nitrogen chemistries were determined with a LECO TC436AR. Both the carbon/sulfur and oxygen/ nitrogen analyses were carried out using NIST certified standards with reported values accurate to $0.0002 \mathrm{wt} \%$.

Prior to fabrication (i.e., hot forging and rolling) and heat treatment, the ingot sidewalls were conditioned on a lathe to 
remove surface imperfections. Each ingot was then given a custom homogenization heat treatment calculated using a combination of CALPHAD estimations and kinetic modeling (Ref 15). The target of the homogenization routine was to reduce the residual chemical inhomogeneities across dendrite arms to within $\pm 1 \%$ of the nominal chemistry. The calculated homogenization heat treatment used for both ingots was as follows: $1100{ }^{\circ} \mathrm{C} / 1 \mathrm{~h}+1180{ }^{\circ} \mathrm{C} / 3 \mathrm{~h}+1200{ }^{\circ} \mathrm{C} / 5 \mathrm{~h}$.

After homogenization, the ingots were placed within stainless steel foil pouches and heated to $800{ }^{\circ} \mathrm{C}$ for $3 \mathrm{~h}$. This provided through thickness heating to the ingot for further hot work. Hot working consisted of upset forging, step flattening, and squaring each ingot into a roughly rectangular shape before hot rolling into plates. The final thickness of the hot worked plates was approximately $10 \mathrm{~mm}$. Thermo-mechanical processing of the ingots from the original size produced in this study to this final shape was sufficient to achieve a fully wrought and equiaxed microstructure.

\subsection{Microstructure Characterization}

HEA1 and HEA2 were examined in the as-cast state, after homogenization, and after hot working using both optical and scanning electron microscopy (SEM). The top flat surface of the hot rolled plates was examined to assess residual grain elongation and directionality. A JEOL JSM 7000F SEM in both backscattered and secondary electron imaging mode was used for all SEM micrographs.

Approximately, 4 mm-thick slices of HEA1 and HEA2 from the homogenized ingots and hot worked plates were cut down into additional slices approximately $0.7 \mathrm{~mm}$ in thickness. Each slice was ground down to $220 \mu \mathrm{m}$, prior to punching out several $3 \mathrm{~mm}$-diameter disks. The disks were ground and polished to a final thickness between 120 and $130 \mu \mathrm{m}$. The disks were electropolished using $100 \mathrm{~mL}$ of $60 \%$ perchloric acid in $900 \mathrm{~mL}$ methanol, at a temperature of $-28{ }^{\circ} \mathrm{C}$. An electropolishing potential of $18 \mathrm{~V}$ was established for HEA1, but there was more difficulty for HEA2. HEA2 had a tendency to etch over the range of voltages explored (17-25 V). The electrolyte used was perhaps not particularly well suited to HEA2, which contained much higher manganese levels when compared to HEA1. After inspecting the polished foils, several were ion milled with a Gatan Precision Ion Polishing System (PIPS). The goal of this was to increase the amount of electrontransparent material.

Ion milling of metal samples is usually avoided due to damage that accumulates in surfaces exposed to highly energized argon ion beams. In order to minimize this effect, a relatively low operating potential $(3 \mathrm{kV})$ was employed. Despite careful operation, some damage was expected, and may present as "black speckled contrast" in bright-field images. The surface damage effect provides additional spots in some of the zone axis diffraction patterns which were accounted for when conducting analyses.

\subsection{Mechanical Testing}

The HEA1 and HEA2 $10 \mathrm{~mm}$-thick rolled plates were sectioned into approximately $10 \mathrm{~mm} \times 10 \mathrm{~mm}$ rectangular cross-section bars that were $76 \mathrm{~mm}$ long. These rectangular bars were subsequently machined into $76 \mathrm{~mm}$-long cylindrical tensile specimens, employing $L=4 D$ geometry for the gage section [per ASTM E8 (Ref 16)] with a reduced section length of $30 \mathrm{~mm}$ and a gage length equal to $25.4 \mathrm{~mm}$ (6.35 $\mathrm{mm}$ gage diameter). Tensile tests were performed according to ASTM E8 (Ref 16) with initial crosshead displacement rate of $0.127 \mathrm{~mm} / \mathrm{min}$ (i.e., an initial strain rate of $8.33 \times 10^{-5} / \mathrm{s}$ for a $25.4 \mathrm{~mm}$ gage length). The extensometer recorded the tensile strain through 0.012 at which point it was removed. Once the extensometer was removed, the crosshead displacement rate was increased to $1.27 \mathrm{~mm} / \mathrm{min}$ for the remainder of the tensile test (i.e., new strain rate equal to $\left.8.33 \times 10^{-4} / \mathrm{s}\right)$. Elongation measurements determined from the recorded crosshead displacement were then verified by measuring the true tensile specimen displacement between gage marks on the reduced section (i.e., gage marks used for elevated temperature extensometer placement). The diameter at the point of fracture in the gage length of the tensile specimen was also measured in order to determine the reduction in area. For elevated temperature testing, the specimen was brought up to the test temperature slowly over several hours so as not to overshoot the desired test temperature. Once the tensile specimen reached the desired test temperature, it was held at that temperature for a minimum of $20 \mathrm{~min}$ before initiation of the test.

\section{Results}

\subsection{Ingot Structure, Alloy Chemistry, Manufacture, and Heat Treatment}

The chemistries of HEA1 and HEA2 (Table 1) are in good agreement with the targeted values. A noteworthy departure is that HEA1 has 0.52 wt.\% Mn. This occurred because HEA1 was melted in the same crucible used to produce HEA2 (containing $\sim 20 \mathrm{wt} . \% \mathrm{Mn}$ ). Part of the residual metal skull leftover in the crucible could not be easily removed; therefore, a small amount of HEA2 was melted into HEA1. Manganese is a common component of stainless steels as well as many types of Ni- and Co-based alloys, and therefore, it should not have a negative impact on properties. Interstitial elements ranged from 40 to $50 \mathrm{ppm}$ oxygen, $>200 \mathrm{ppm}$ sulfur and nitrogen, and 300 to $400 \mathrm{ppm}$ carbon. These elements have rarely been reported in HEA literature, and therefore, it is unclear how these values compare with other studies. Comparing the interstitial levels to acceptable ranges found in high performance nickel superalloys, the values obtained herein were higher than desired, but may still be low enough to avoid detrimental effects to mechanical behavior. These trace elements will likely manifest as oxides, nitrides, carbides, and carbo-nitrides. The sulfur

Table 1 Design (upper) and measured (lower) compositions of HEA1 and HEA2

\begin{tabular}{|c|c|c|c|c|c|c|c|c|c|}
\hline & $\mathrm{Cr}$ & $\mathbf{N i}$ & Co & $\mathbf{F e}$ & Mn & $\mathrm{C}$ & $\mathbf{N}$ & $\mathbf{O}$ & $\mathbf{S}$ \\
\hline Aim & 23.06 & 26.04 & 26.13 & 24.77 & - & & & & \\
\hline HEA1 & 22.66 & 25.89 & 26.00 & 24.85 & 0.51 & 0.039 & 0.027 & 0.005 & 0.024 \\
\hline Aim & 18.54 & 20.93 & 21.01 & 19.93 & 19.59 & & & & \\
\hline HEA2 & 19.14 & 21.47 & 21.68 & 17.39 & 20.27 & 0.032 & 0.026 & 0.004 & 0.024 \\
\hline
\end{tabular}


levels were quite high and were expected to form Mn-rich sulfides. SEM and TEM investigations were used to identify these precipitates.

SEM of HEA1 and HEA2 in the as-cast condition showed a dendritic structure typically seen in castings (Ref 14). The X-ray maps of the constituent elements illustrated how $\mathrm{Co}, \mathrm{Cr}$, and $\mathrm{Fe}$ partition to the dendrite core, while $\mathrm{Mn}$ and Ni partition to the interdendritic region (Ref 14). In order to reduce segregation, homogenization of the as-cast structures of HEA1 and HEA2 was performed using NETL's computational approach (Ref 15). Doing so greatly reduced the chemical inhomogeneity due to solidification segregation (Ref 14).

After the homogenization heat treatment step, the ingots were thermo-mechanically processed. During and after the hot working step, HEA1 and HEA2 showed no signs of surface or edge defects. The hot working temperature of $800^{\circ} \mathrm{C}$ was selected as a compromise to allow both alloys to be forged simultaneously while enhancing grain refinement. The hot working temperature was 0.6 and 0.7 of the computed homologous temperature for HEA1 and HEA2, respectively. Careful attention to grain refinement during hot working was important as neither alloy contained secondary phases to inhibit grain growth.

\subsection{Microstructure Characterization}

The overall structure of the wrought alloys contained a mixture of equiaxed and residual wrought grains (Ref 14). Several elongated second phase particles were also evident and were investigated via SEM along with other microstructural characteristics. SEM backscattered electron imaging indicated that aside from the elongated secondary phase, neither alloy contained additional anomalous phases (Ref 14). The grains were also moderately twinned (common for FCC crystal structure materials). The elongated secondary phases were rich in $\mathrm{Mn}$ and $\mathrm{S}$ and are likely $\mathrm{MnS}$ particles. These particles likely formed during casting did not dissolve below the $800{ }^{\circ} \mathrm{C}$ hot working temperature, and subsequently elongated during hot rolling operations.

X-ray energy dispersive spectroscopy (XEDS) via TEM was used to characterize the local chemistries of HEA1 and HEA2 (Table 2). These spectra were collected from featureless regions within two adjacent grains, and the reported values are the averages between the two grains. The results suggest that the regions sampled are in reasonable agreement with the bulk XRF analysis. Transmission electron microscopy (TEM) of HEA1 and HEA2 confirmed that even at a local scale each alloy only had the occasional inclusion of $\mathrm{MnS}$, or Si-/Al-rich oxides. Inclusions such as these are expected when producing alloys via industrial methods. While the presence of inclusions should be noted, they were present in small volume fractions so their influence on alloy performance is likely minimal.

Further TEM investigations revealed that high-angle grain boundaries in HEA1 and HEA2 were free of second phase particles (Fig. 1). HEA1 also contained several low-angle boundaries, most probably twin boundaries, which were also free of secondary phases. Revisiting these boundaries under

Table 2 Composition analysis comparison between the bulk (XRF) and local scale in the TEM

\begin{tabular}{lllrrr}
\hline & & Co & Cr & Fe & Mn \\
\hline \multirow{2}{*}{ HEA1 } & XRF & 26.00 & 22.66 & 24.85 & 25.89 \\
& TEM & 23.60 & 26.30 & 24.90 & 17.39 \\
HEA2 & XRF & 21.68 & 19.14 & 24.30 \\
& TEM & 18.05 & 19.15 & 21.47 \\
\hline
\end{tabular}
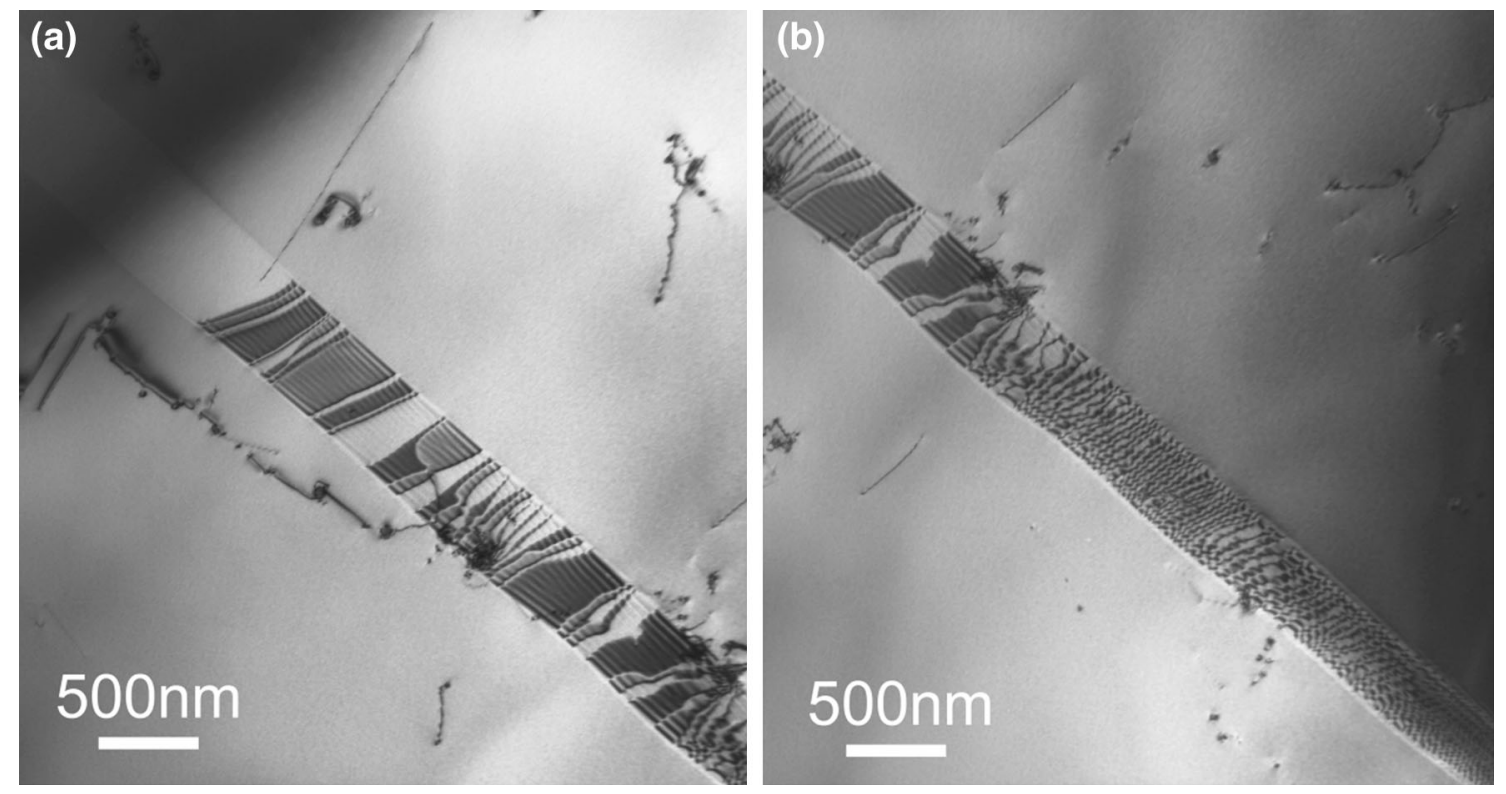

Fig. 1 TEM image of HEA1 that highlights the single-phase nature of the alloy. Foil thickness fringe contrast and dislocations on a low-angle boundary. $g=111$ near a $\langle 110\rangle$ zone axis 

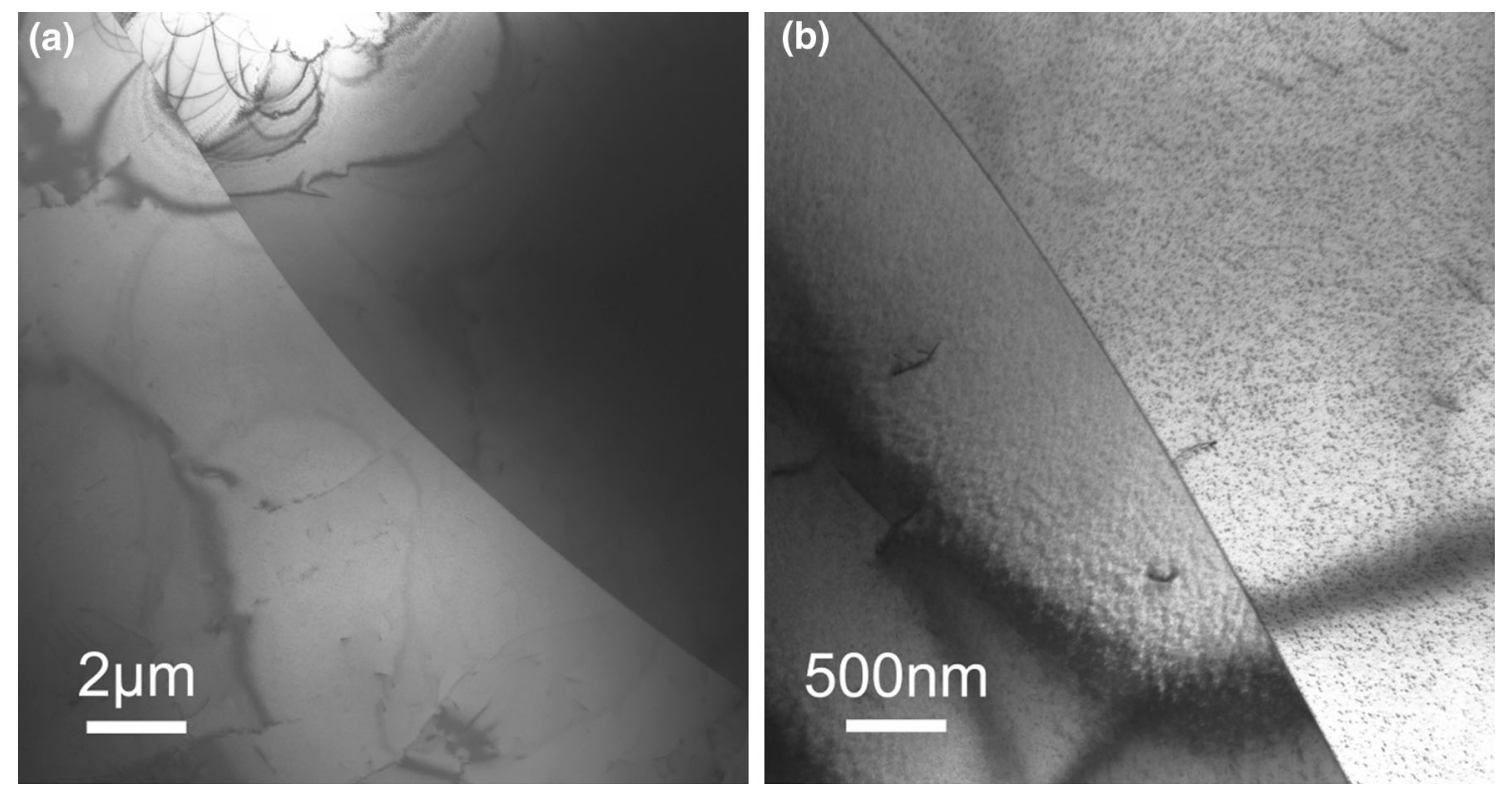

Fig. 2 TEM images of HEA2 showing single-phase nature of alloy. Image on the left is a low magnification image showing high-angle grain boundary in the center of the image. Note the absence of any precipitates along the grain boundary or in the matrix. A higher magnification image is shown on the right (B) and aside from the ion milling damage it supports the single-phase nature of HEA2

Table 3 Tensile mechanical properties for HEA1 as function of temperature

\begin{tabular}{lcccc}
\hline Temperature, ${ }^{\circ} \mathbf{C}$ & $\mathbf{0 . 2 \%}$ YS, MPa & UTS, MPa & Elongation, \% & RA, \% \\
\hline RT $(23)$ & 611 & 794 & 38 & 60 \\
250 & 527 & 643 & 26 & 57 \\
500 & 484 & 579 & 26 & 34 \\
600 & 415 & 349 & 29 & 29 \\
700 & 244 & 174 & 64 & 49 \\
800 & 103 & & & \\
\hline
\end{tabular}

Table 4 Tensile mechanical properties for HEA2 as function of temperature

\begin{tabular}{lcccc}
\hline Temperature, ${ }^{\circ} \mathbf{C}$ & $\mathbf{0 . 2 \%}$ YS, MPa & UTS, MPa & Elong., \% & RA, \% \\
\hline RT $(23)$ & 537 & 719 & 39 & 29 \\
250 & 451 & 588 & 24 & 68 \\
500 & 437 & 539 & 22 & 14 \\
600 & 355 & 475 & 23 \\
700 & 215 & 155 & 22 & 14 \\
800 & 93 & & 23 \\
\hline
\end{tabular}

higher magnification and utilizing SAD from the adjacent regions revealed what may be interpreted as narrow twinned region. Again no secondary phases were evident near this feature. In depth TEM of HEA2 (Fig. 2) revealed many of the same characteristics as HEA1 with no significant secondary phases aside from those that are inherent to the materials and processes used in the current study (i.e., sulfide/oxide inclusions).

\subsection{Mechanical Properties}

Table 3 contains the tensile mechanical properties measured for HEA1. Table 4 contains the same information for HEA2. HEA1 possessed slightly higher yield and tensile strengths compared to HEA2 for all temperatures tested. The decrease in yield and tensile strength was fairly gradual through $600{ }^{\circ} \mathrm{C}$ at which point the decrease in yield and tensile strength increased slightly, leading to a steeper decline in both values through the $800{ }^{\circ} \mathrm{C}$ test. Ductility as measured either by elongation to failure or as reduction in area was good at room temperature with an elongation to failure of 38 and 39\% for HEA1 and HEA2, respectively. Corresponding values of reduction in area were 60 and $68 \%$, respectively, for HEA1 and HEA2. For HEA1, ductility decreased at each test temperature, reaching a minimum in elongation for the test conducted at $600{ }^{\circ} \mathrm{C}$ (i.e., elongation to failure was $20 \%$ ). Tensile tests at 700 and $800{ }^{\circ} \mathrm{C}$ showed increases in overall elongation at failure, reaching 29 and $64 \%$, respectively. [Note: The reduction in area decreased in HEA1 through the test at $700{ }^{\circ} \mathrm{C}$ before increasing at 


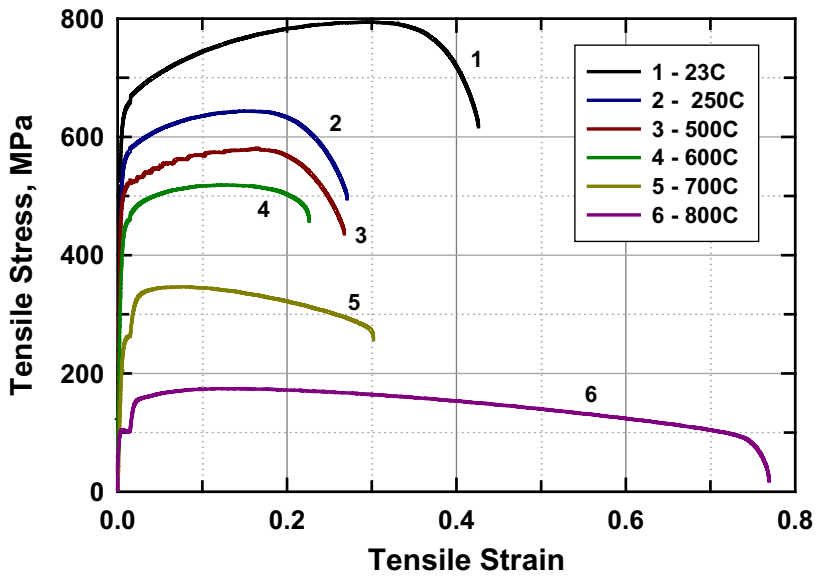

Fig. 3 Representative stress-strain curves for HEA1. Note serration for selected elevated temperature testing conditions. Behavior of HEA2 was similar to that of HEA1 and is not shown

$800{ }^{\circ} \mathrm{C}$.] Values of ductility for HEA2 were equivalent to, or slightly better than, HEA1 at room temperature and $250^{\circ} \mathrm{C}$. For the tensile tests starting at $500{ }^{\circ} \mathrm{C}$ ductility measures, either in terms of elongation to failure or reduction in area, were less than those observed for HEA1. The minimum in ductility for HEA2 was reached at $700{ }^{\circ} \mathrm{C}$ where the elongation at failure dipped to a low of $14 \%$ before increasing again at $800{ }^{\circ} \mathrm{C}$ (i.e., elongation to failure was $22 \%$ at this temperature). The same trend occurred in terms of reduction in area for HEA2 with roughly the same numerical values as was observed for elongation to failure (Table 4).

Figure 3 shows the stress-stain curves from tensile tests performed on HEA1 (HEA2 had similar stress-stain curves). Both alloys showed appreciable evidence of work hardening at least through the $500^{\circ} \mathrm{C}$ tensile test. From inspection of the tensile stress-strain curves, serrations were observed for HEA1 and HEA2 at $500{ }^{\circ} \mathrm{C}$, while they are absent at the other temperatures tested.

\subsection{Fracture Behavior}

After tensile testing, selected specimen fracture surfaces were examined in the scanning electron microscope to assess fracture characteristics. From the mechanical property measurements, ductility in HEA1 and HEA2 was quite high at room temperature, with elongations to fracture of 38 and $39 \%$, respectively. In looking at the fracture surface of HEA1, ductile fracture features were abundant (see Fig. 4). The fracture surface was characterized by small voids mostly uniform in size but interspersed with some larger dimples. The fracture surface in Fig. 4 is typical of transgranular plastic growth of voids during tensile deformation (Ref 17).

Associated with many of the large dimples were precipitates (see Fig. 5). As noted previously, MnS and other oxide-based precipitates from impurities in the starting feedstock were found throughout the microstructure, usually isolated from each other. This is supported in the SEM investigations of the fracture surfaces. Generally, the fracture morphology consists of large regions of uniform fine dimples typical of transgranular plastic void nucleation and growth during tension testing of precipitate free material. As mentioned, interspersed between these regions are some larger dimples and associated with each

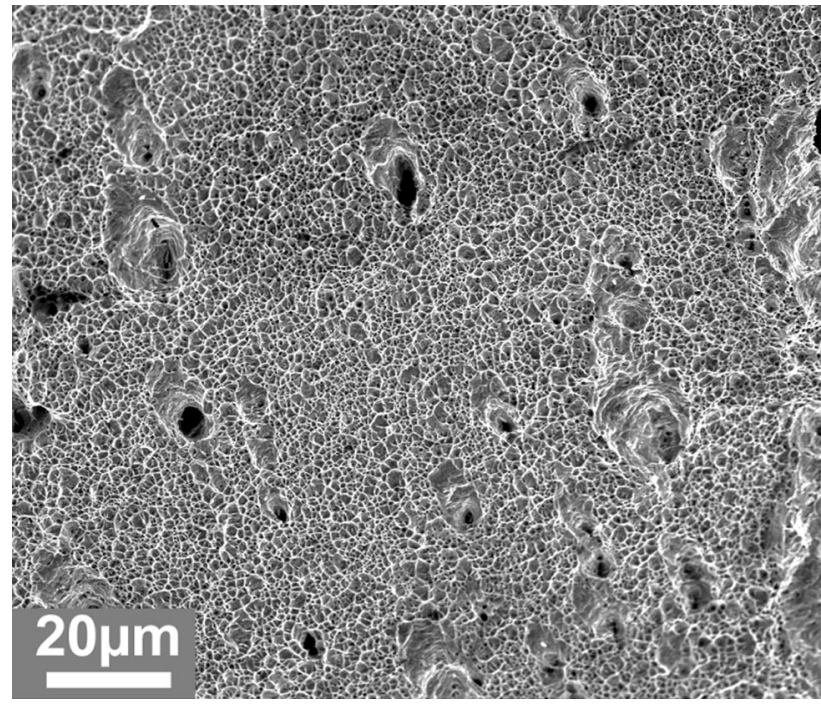

Fig. 4 Fracture surface of HEA1 after tensile testing at room temperature, showing the combination of random large dimples interspersed with smaller more uniform ones

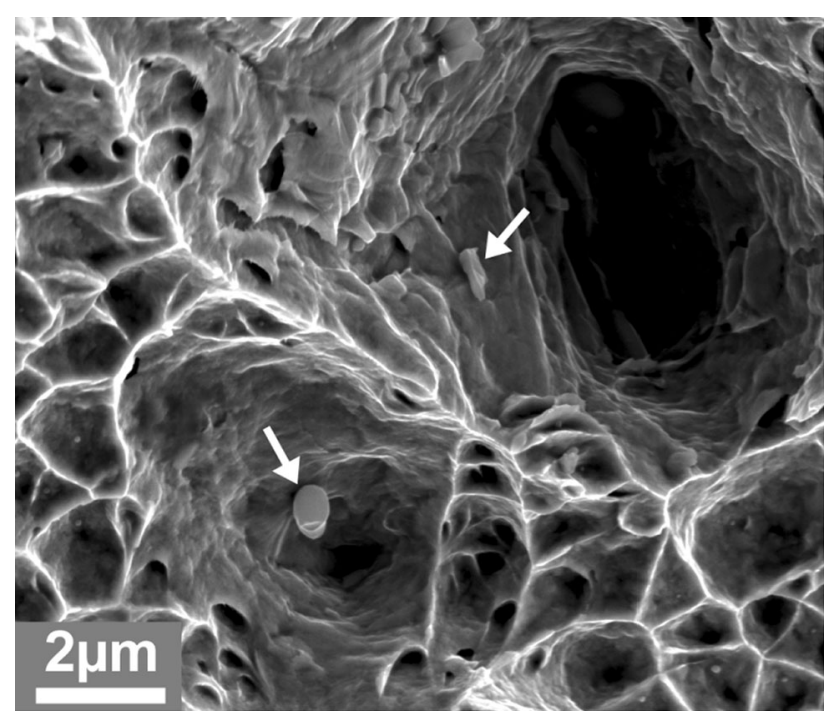

Fig. 5 High magnification image of the room temperature tensile fracture surface showing the MnS particles in the larger dimples

of these large dimples is a precipitate of some type. In HEA1, the precipitate found in the base of the most of these dimples is $\mathrm{MnS}$. The MnS precipitate is mostly associated with steel, and three variants have been noted: Type I inclusions which are globular and form in rimming steels; Type II inclusions with an interdendritic structure are found in killed steels; and Type III angular inclusions which are formed in fully deoxidized steels (Ref 18). HEA1 had a rather large sulfur content, leading to a more significant fraction of $\mathrm{MnS}$ precipitates. Examination of the morphology of the MnS precipitates in Fig. 5 suggests both Type I and Type III variants in HEA1. However, it appears the ductility in HEA1 (at least in the longitudinal, or rolling, direction) was little affected by the $\mathrm{MnS}$ precipitate fraction.

The fracture surface of HEA2 was very much the same as that of HEA1 after testing at room temperature. Aside from 


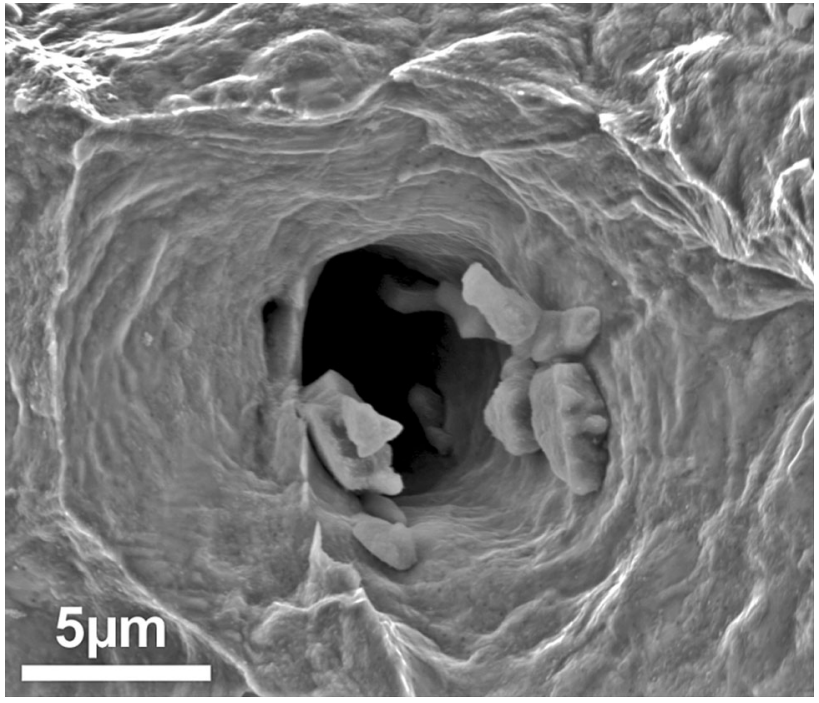

Fig. 6 Large dimple in HEA2 after room temperature tensile test showing clearly a number of $\mathrm{MnS}$ precipitates

some minor oxidation on the fracture surface after testing at $500{ }^{\circ} \mathrm{C}$ (due to surface exposure to atmosphere during cool down), the ductile nature of the alloy is much the same as seen at room temperature. The elongation to failure of HEA1 and HEA2 at $500{ }^{\circ} \mathrm{C}$ was 26 and $24 \%$, respectively. The fracture surface was characterized by somewhat larger dimples interspersed with regions of minimal ductility (i.e., "flatter" surface feature effects, not shown). While not strictly a "creep test" such that growth of the voids occurs by power law creep, the appearance of larger voids suggests an additional deformation mechanism, most probably due to the testing temperature. As seen at room temperature, these larger dimples on the fracture surface of HEA2 after testing at $500{ }^{\circ} \mathrm{C}$ have an associated precipitate (see Fig. 6). In this case, the precipitate is $\mathrm{MnS}$. Again this precipitate formed due to the tramp sulfur within the feed materials is used to make these alloys. The fracture surfaces at $800{ }^{\circ} \mathrm{C}$ showed more oxidation than seen at $500{ }^{\circ} \mathrm{C}$, obscuring fine fracture detail. They are not shown.

\section{Discussion}

\subsection{Ingot Structure, Alloy Chemistry, Manufacture, and Heat Treatment}

Vacuum induction melt-produced ingots exhibit the classic grain morphology seen in many text books with a thin outer zone of chill grain, a columnar grained zone extending inward, and an equiaxed grained zone in the center. The machining and hot working techniques employed in the current study broke down this structure and refined it. HEA1 and HEA2 underwent reductions of approximately $88 \%$ during hot working from ingot form to a $10 \mathrm{~mm}$-thick plate. The extent to which a material's grain structure may be altered via hot work is limited by its initial and desired final geometries.

The homogenization heat treatment was quite effective in reducing segregation within the alloys. In order to achieve the $\pm 1 \%$ chemistry variation target in a practical heat treat duration, a multi-step homogenization cycle was necessary. The first step in the homogenization cycle allowed elements enough time to diffuse in the segregated regions so that the melting point within the interdendritic regions increased. Subsequent homogenization cycle steps then utilized higher and higher temperatures, with corresponding increase of the soak time to achieve the homogenization target. As an example, a casting may be heated to within $50{ }^{\circ} \mathrm{C}$ of its incipient melt point (calculated based on chemistry of the interdendritic region). Kinetic models are then used to estimate the chemical change in the interdendritic region after a certain amount of time at the initial temperature. After the new chemistry is calculated, a new interdendritic liquidus can be determined and used to guide increases to the heat treatment temperature.

The amount of oxygen, nitrogen, carbon, and sulfur in both HEA1 and HEA2 was higher than desired. High-purity materials were used consistent with industry standards rather than ultra-high-purity laboratory grade materials. The interstitial elements were carried by the feed materials into the melt, and control of these elements is a day-to-day concern of many alloy producers. As such, some discussion is needed on the potential and observed impacts of these contaminants. The carbon and nitrogen might be anticipated to form carbides or carbo-nitrides (especially with $\mathrm{Cr}$ ). Oxygen is expected to form various metal oxides. While neither carbides nor carbo-nitrides were observed, oxides were occasionally found (and were observed in both SEM and TEM investigations). The sulfur would be expected to form sulfides (especially with $\mathrm{Mn}$ ) and many of these precipitates segregated to grain boundaries. Sulfur is the least desirable and most problematic. Suspected manganese sulfides were observed in both alloys via SEM and TEM. Fortunately, the presence of the sulfides did not influence the hot workability of these alloys, nor did they appear to have a significant effect on mechanical performance. Although it was not done in the current study, sulfur can be removed in the melt by reacting with elements such as yttrium (Ref 19).

\subsection{Microstructure}

The wrought microstructures of HEA1 and HEA2 revealed that the as-cast dendrite structure was fully refined with fine $(<25 \mu \mathrm{m})$, equiaxed grains forming as a result of hot working. The fine grain size may be attributable both to the relatively low hot working temperature as well as sluggish diffusion observed in HEAs (Ref 1, 4). There were also, unfortunately, some residual areas that did not recrystallize as a result of the final 15 min hold within the $800{ }^{\circ} \mathrm{C}$ furnace. The residual worked areas (likely due to the same factors influencing grain size) are not generally desirable. A higher hot working temperature may be needed in order to prevent their formation. Post-work heat treatment is also an option; however, this was not used in the current study due to the unknown grain growth kinetics of both alloys.

Electron microscopy of HEA1 and HEA2, especially TEM, revealed that each was essentially single phase with oxide and sulfide inclusions. No secondary phases based on the HEA elements were observed at either the grain boundaries or twin boundaries. The combination of analytical techniques utilized showed that these alloys have a FCC matrix and the desired chemistry.

\subsection{Mechanical Properties}

A number of individuals have looked at the single-phase HEAs described in this work in terms of processing, microstructure, and mechanical behavior (Ref 20-25). In 
particular, trying to compare the tensile mechanical properties of HEAs is difficult given the many ways the alloys have been manufactured (i.e., melting procedure, solidification route, heat treatments including homogenization approach, fabrication methodology). Complications invariably arise due to variations in grain size, the possibility of residual segregation (which may not have been characterized), leading to possible phase formation (intentional or otherwise), starting dislocation density, etc. Given these concerns, several papers have been published specifically on either the compressive or tensile properties of CoCrFeNi and CoCrFeNiMn (Ref 22-25).

Also, another factor to keep in mind when comparing tensile data from the testing done in this research with other information found in the literature is the tensile specimen size difference. In research reported herein, ASTM E8 was adhered to for tensile specimen preparation, meaning that cylindrical tensile test specimens, $>76 \mathrm{~mm}$ in length with a reduced gage section equivalent to $30 \mathrm{~mm}$ in length with $6.35 \mathrm{~mm}$ in diameter, were used. These specimens were extracted and machined from plate about $12 \mathrm{~mm}$ in thickness. As such they were considerably larger than those used in comparison studies found in the literature (Ref 22-25). Actual tensile testing was also performed according to ASTM E8, meaning after yield the crosshead displacement rate was increased for the remainder of the test (i.e., from 0.127 to $1.27 \mathrm{~mm} / \mathrm{min}$, corresponding to an effective strain rate increase from $8.33 \times 10^{-5}$ to $8.33 \times 10^{-4} / \mathrm{s}$ when using a $25.4 \mathrm{~mm}$ gage length extensometer).

Compression testing was performed in (Ref 24) using strain rates between $10^{-4}$ and $10^{-2} / \mathrm{s}$ at temperatures between 600 and $800{ }^{\circ} \mathrm{C}$ at $100{ }^{\circ} \mathrm{C}$ intervals. From the compression tests, yield stress and flow stress proved to be the most relevant for comparison purposes. While a direct comparison was impossible, the flow stress for "HEA2" type material was between $282 \mathrm{MPa}\left(10^{-4} / \mathrm{s}\right)$ and $375 \mathrm{MPa}\left(10^{-3} / \mathrm{s}\right)$ at $700^{\circ} \mathrm{C}$ and $174 \mathrm{MPa}\left(10^{-4} / \mathrm{s}\right)$ and $264 \mathrm{MPa}\left(10^{-3} / \mathrm{s}\right)$ at $800^{\circ} \mathrm{C}$. At $700{ }^{\circ} \mathrm{C}$, HEA2 had an approximate flow stress (UTS value) of $321 \mathrm{MPa}$. This falls within the values measured in Ref 24. At $800{ }^{\circ} \mathrm{C}, \mathrm{HEA} 2 \mathrm{had}$ an approximate flow stress (UTS value) of $155 \mathrm{MPa}$, which was a bit lower than was observed in Ref 24 for compression. However, given the possible reasons for these differences as noted above, the magnitude similarity is surprisingly good.

Zaddach et al. (Ref 25) looked at HEA1- and HEA2-type chemistries and performed tensile tests at room temperature. The one major difference was that the tensile specimens were "annealed" for a period of time at either $1100{ }^{\circ} \mathrm{C}$ or $625 /$ $650{ }^{\circ} \mathrm{C}$ after thermo-mechanical processing (TMP) but prior to testing. The corresponding NETL material was also given a short duration post-TMP heat treatment during plate flattening process. For the $\mathrm{NiFeCrCo}$ material (corresponding to HEA1) annealed at $1100{ }^{\circ} \mathrm{C}$, the room temperature tensile properties were $197 \mathrm{MPa}(0.2 \% \mathrm{YS}), 582 \mathrm{MPa}$ (UTS), and 82\% (Elongation). Conversely, when annealed at only $625^{\circ} \mathrm{C}$, the tensile properties for the $\mathrm{NiFeCrCo}$ material were $540 \mathrm{MPa}(0.2 \%$ YS), $786 \mathrm{MPa}$ (UTS), and 49\% (Elongation). The amount of recovery in the material was more significant at the higher postTMP process temperature. For HEA1, corresponding to $\mathrm{NiFeCrCo}$, the measured tensile properties at room temperature [see Table 3] were $611 \mathrm{MPa}(0.2 \%$ YS), $794 \mathrm{MPa}$ (UTS), and $38 \%$ (Elongation), or slightly higher values in strength and a bit lower in ductility as measured by elongation at failure than observed in the Zaddach et al. research (Ref 25).
For HEA2-type material (i.e., NiFeCrCoMn), Zaddach et al. (Ref 25) measured tensile properties at room temperature to be (1) $135 \mathrm{MPa}(0.2 \% \mathrm{YS}), 497 \mathrm{MPa}$ (UTS), and 55\% (Elongation) for $1100{ }^{\circ} \mathrm{C}$ annealed material and (2) $660 \mathrm{MPa}(0.2 \%$ YS), $851 \mathrm{MPa}$ (UTS), and $25 \%$ (Elongation) for $650{ }^{\circ} \mathrm{C}$ annealed material. The tensile properties for HEA2 fell within this range at $538 \mathrm{MPa}(0.2 \% \mathrm{YS}), 725 \mathrm{MPa}$ (UTS), and $40 \%$ (Elongation) [see Table 4]. The trend in strength and ductility was consistent between the two sets of materials even accounting for the discrepancies in the processing of materials for testing.

The mechanical properties of HEA1 and HEA2 are both encouraging and intriguing (Tables 3 and 4; Fig. 7 and 8). By comparing the room temperature mechanical performance of HEA1 and HEA2 (Tables 3 and 4) to typical room temperature properties from select 300-series austenitic stainless steels (Table 5), it can be seen that the HEA alloys can outperform these alloys in yield stress and ultimate tensile strength with

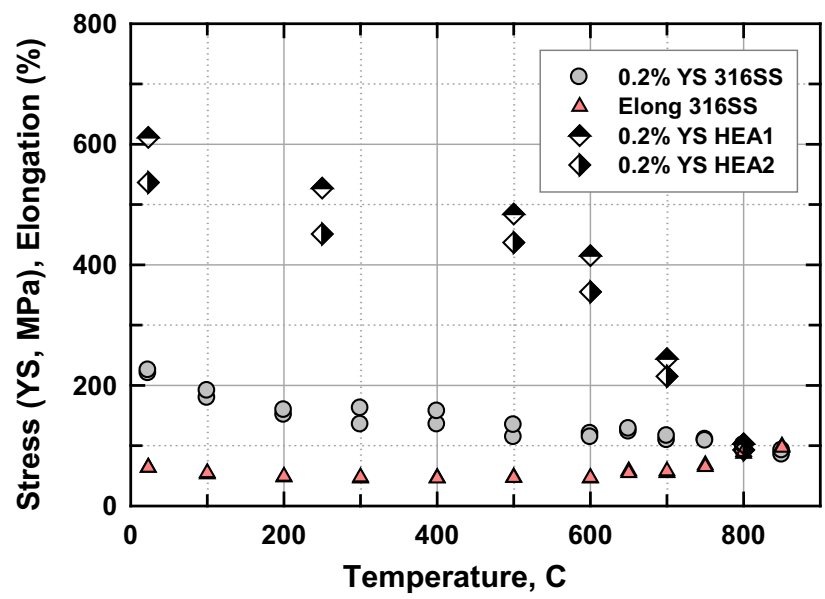

Fig. 7 Tensile behavior for $316 \mathrm{SS}$ as a function of test temperature. Values of $0.2 \%$ YS for HEA1 and HEA2 are also shown on the graph [22]

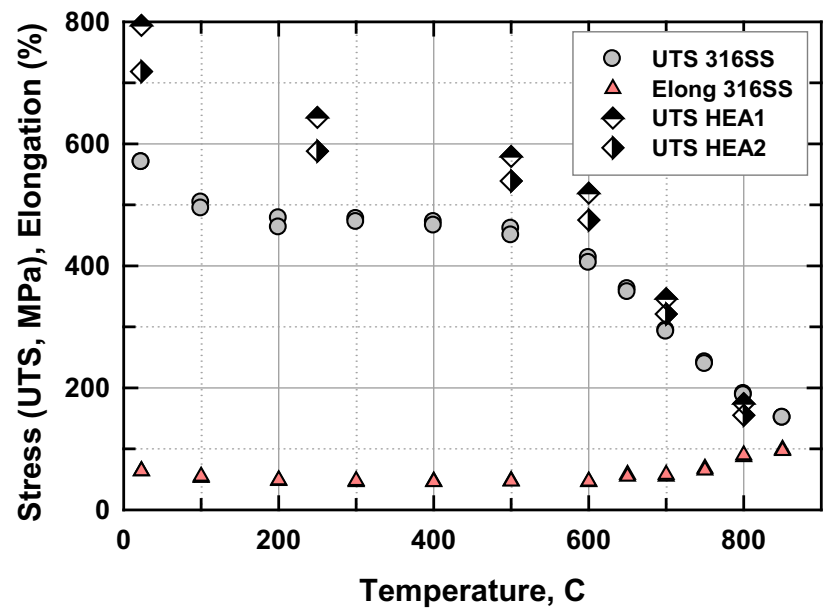

Fig. 8 Tensile behavior for $316 \mathrm{SS}$ as a function of test temperature. Values of UTS for HEA1 and HEA2 are also shown on the graph [22] 
Table 5 Typical minimum room temperature tensile properties for selected austenitic stainless steels [21]

\begin{tabular}{lccccc}
\hline Steel grade & UNS No. & $\mathbf{0 . 2} \%$ YS, MPa & UTS, MPa & Elong., \% & Ratio [YS/UTS] \\
\hline 304 & S30400 & 205 & 515 & 40 & 0.40 \\
304L & S30403 & 170 & 480 & 60 & 0.35 \\
304LN & S31653 & 205 & 515 & 35 & 0.40 \\
304N & S30451 & 240 & 550 & 40 & 0.44 \\
310 S & S31008 & 205 & 515 & 40 & 0.40 \\
316 & S31600 & 205 & 515 & 30 & 0.40 \\
$316 \mathrm{~N}$ & S31651 & 240 & 550 & 35 & 0.44 \\
$317 \mathrm{~L}$ & S31703 & 205 & 515 & 40 & 0.40 \\
321 & S32100 & 205 & 515 & 40 & 0.40 \\
347 & S34700 & 205 & 515 & & 0.40 \\
\hline
\end{tabular}

Table 6 Ratio of YS to UTS for HEA1, HEA2, and 316 SS [22] as function of temperature

\begin{tabular}{lccc}
\hline Test temperature, ${ }^{\circ} \mathrm{C}$ & [YS/UTS] HEA1 & [YS/UTS] HEA2 & [YS/UTS] 316SS \\
\hline RT $(23)$ & 0.77 & 0.75 & 0.39 \\
250 & 0.82 & 0.77 & - \\
500 & 0.84 & 0.81 & 0.26 \\
600 & 0.80 & 0.75 & 0.29 \\
700 & 0.71 & 0.67 & 0.38 \\
800 & 0.59 & 0.60 & 0.48 \\
\hline
\end{tabular}

little sacrifice in ductility. As shown in Ref 25 , it is possible to modify the yield stress and ultimate tensile strength by heat treatment. Austenitic stainless steels typically have low yield stress (on purpose) and then work harden considerably. They also have very good ductility with values of elongation at failure $>35 \%$ except for some of the specialty variants (i.e., $316 \mathrm{~N})$. Austenitic stainless steels also have good toughness. Consequently, 300-series austenitic stainless steels typically have a low ratio of yield stress to ultimate tensile strength [YS/ UTS], usually in the range of 0.35 to 0.45 . HEA1 and HEA2 in comparison have a [YS/UTS] of around 0.75. These two HEAs have a higher yield stress in comparison to the austenitic stainless steels, while their tensile strength is higher. On the other hand, the material produced by Zaddach et al. (Ref 25) showed very different values of [YS/UTS] depending on the post-TMP heat treatment. For example, for NiFeCrCo material, the ratio of [YS/UTS] when given a post-TMP heat treatment at $1100{ }^{\circ} \mathrm{C}$ was 0.34 , similar to austenitic stainless steel. Alternatively, when given the lower temperature post-TMP heat treatment $\left(625^{\circ} \mathrm{C}\right)$, the [YS/UTS] ratio increased to 0.69 , or similar to the HEA1 alloy. The same behavior in [YS/UTS] ratio was also observed in $\mathrm{NiFeCrCoMn}$ material (i.e., 0.27 and 0.78). It should be acknowledged that the slightly lower ductility in the present HEA alloys may be partial due to the fine grain structure observed in these alloys as well as the residual wrought grains/regions which would be expected to also impact the yield strength.

Nevertheless, the room temperature ductility remains high in the HEA alloys. A comparison of [YS/UTS] of HEA1, HEA2, and $316 \mathrm{SS}$ is made in Table 6 at various test temperatures (Ref 26). At all test temperatures considered, the HEA alloys had a significantly higher [YS/UTS] ratio compared to $316 \mathrm{SS}$, sometimes by a factor of more than $2 \times$. The yield stress and ultimate tensile strength of the HEA alloys are further compared to $316 \mathrm{SS}$ as a function of temperature in Fig. 7 and 8 (Ref 26). The differences in yield stress are substantial throughout the temperature range tested (Fig. 7), while the differences in ultimate tensile strength are less so (Fig. 8) but still significant through most of the temperature range (at $700{ }^{\circ} \mathrm{C}$ the UTS values for the HEA alloys begin to converge with those of $316 \mathrm{SS}$ ). The main difference between $316 \mathrm{SS}$ and the HEA alloys is the ductility. For example, in the HEA alloys, ductility as measured by elongation to fracture decreases from room temperature to either $600{ }^{\circ} \mathrm{C}$ (HEA1) or $700{ }^{\circ} \mathrm{C}$ (HEA2) before increasing again at higher temperatures. Alloy $316 \mathrm{SS}$ also exhibits a ductility decrease. However, the decrease is less deep going from about $64 \%$ at room temperature to about $46.5 \%$ at $400{ }^{\circ} \mathrm{C}(\operatorname{Ref} 26)$. If the ratio of ductility at the minimum is compared to that at room temperature, the difference is quite apparent: $316 \mathrm{SS} \quad\left[e_{400 \mathrm{C}} / e_{\mathrm{RT}}\right]=0.73 ;$ HEA1 $\left[e_{600 \mathrm{C}} /\right.$ $\left.e_{\mathrm{RT}}\right]=0.53$; HEA2 $\left[e_{700 \mathrm{C}} / e_{\mathrm{RT}}\right]=0.36$. In order to understand this behavior, differences in the microstructure and how each material behaves under load will have to be better understood.

The intriguing tensile performance of HEA1 and HEA2 is further revealed upon examination of their tensile curves (Fig. 3). Besides the high work hardening rate observed at most temperatures, the curve at $500{ }^{\circ} \mathrm{C}$ is a bit erratic. This behavior, i.e., serrations in the stress-stain curve at elevated temperatures, has been reported in other high-entropy alloy research (Ref 4). At room temperature, the stress-strain curves for HEA1 and HEA2 are representative of typical FCC materials, i.e., gradual increase in stress with increasing strain (i.e., work hardening) until maximum load is reached. As the temperature of the tensile test increases, the amount of work hardening decreases with the point of maximum load (corresponding to UTS) shifting to lower values of strain. At $800{ }^{\circ} \mathrm{C}$, maximum load occurs shortly after yield with a more pronounced region of flow stress (i.e., minor variation in stress with increasing strain, and in this case it decreases slightly (from an engineering stress-strain perspective) with increasing strain until failure).

As stated before, serrated flow was observed during tensile tests at $500{ }^{\circ} \mathrm{C}$. Serrated or "jerky" flow is a well-known phenomenon that has been extensively studied due to its negative effects on the surface of forged components. Serrated flow has several potential causes including formation of twins, 
stress-induced martensitic transformations, or interactions between solute atoms and dislocations (Ref 27-29). The latter of these mechanisms is often referred to as the Portevin-Le Chatelier effect. As the temperature of a tensile specimen is increased, solute atoms may achieve sufficient mobility to move to, and effectively pin, dislocations until the applied stress overcomes the pinning effect. The result is a marked decrease in measured stress as the material deforms rapidly until the process begins to repeat itself leading to the serrated pattern in the stressstrain curve. As the temperature of a sample is further increased, additional pathways for solute atom mobility may become available leading to less intense interactions between solute atoms and dislocations causing the Portevin-Le Chatelier effect to diminish. This behavior is observed in the current set of experiments with serrated flow becoming active at around $500{ }^{\circ} \mathrm{C}$ and vanishing at $600{ }^{\circ} \mathrm{C}$. An additional characteristic of the Portevin-Le Chatelier effect is a minimum in ductility (Ref 28). In both the HEAs studied, there was a decrease in ductility as the serrated flow became active. For these reasons it is most likely that solute atoms are pinning dislocations in the alloys that were studied. This effect has also been well documented in several other investigations on similar HEA systems (Ref 4).

In HEAs, it is difficult to define which element is the solute, and therefore, there exists significant ambiguity as to which element is primarily responsible for dislocation pinning. On a practical note, the serrated flow deactivated well below temperatures that would be used in hot forming operations. This means that any surface imperfections related to the Portevin-Le Chatelier effect should not be an issue. If the HEAs under study were to be used at service temperatures between 500 and $600{ }^{\circ} \mathrm{C}$, there are also means by which this effect can be minimized including introducing cold work to the material.

\subsection{Plastic Deformation}

Extensive deformation occurred during tensile testing with features of the microstructure being largely obscured by the strain effects due to dislocation generation typical in FCC structures. It was observed in the non-deformed microstructures that some twinning had occurred, most probably during deformation processing/heat treatment stages. Inspection of Fig. 9 shows that in addition to the indistinct regions of high dislocation density, extensive twinning also occurs. The twins in this figure represent some of the larger ones with many much finer than these in width/ spacing. The arrows represent grain boundaries which were difficult to resolve due to the very high dislocation density and strain therein. Twin width/spacing varied from about $10 \mathrm{~nm}$ to the $50 \mathrm{~nm}$, or slightly greater, as seen in Fig. 9.

In Fig. 10, there appears to be many nano-sized dislocationfree regions. At first these regions were thought to be an anomaly from the thinning process. However, upon further inspection, it is more likely that these regions represent a reorganization of the dislocations into a cellular structure that due to specimen preparation are resolvable in the manner seen in Fig. 10. These dislocation-free regions are roughly 100 to $150 \mathrm{~nm}$ in width. Considering the very small dimple size from the room temperature fracture surface, these structural units can be envisioned to have evolved into the dimpled structure during tensile deformation on the fracture surface as the concentration of dislocation in the "wall" sections of the cell increased until cracks started forming. Subsequent growth and coalescence of these cells resulted in the fine dimpled nature of the fracture surface.

One apparent difference between the microstructure of the deformed material tested at room temperature and that tested at $500{ }^{\circ} \mathrm{C}$ is the increase in grain size (see Fig. 11). While the apparent dislocation density is still quite high, meaning it was impossible to resolve any fine features associated with individual dislocations, grain boundaries or precipitates in these areas of the microstructure, the apparent grain size appears larger (as seen by contrast changes resulting from specimen tilting for the grain in the center of the image in Fig. 11). Another structural change seems to be in the size and frequency of twins. In the specimen tested at $500{ }^{\circ} \mathrm{C}$, the size of the twins
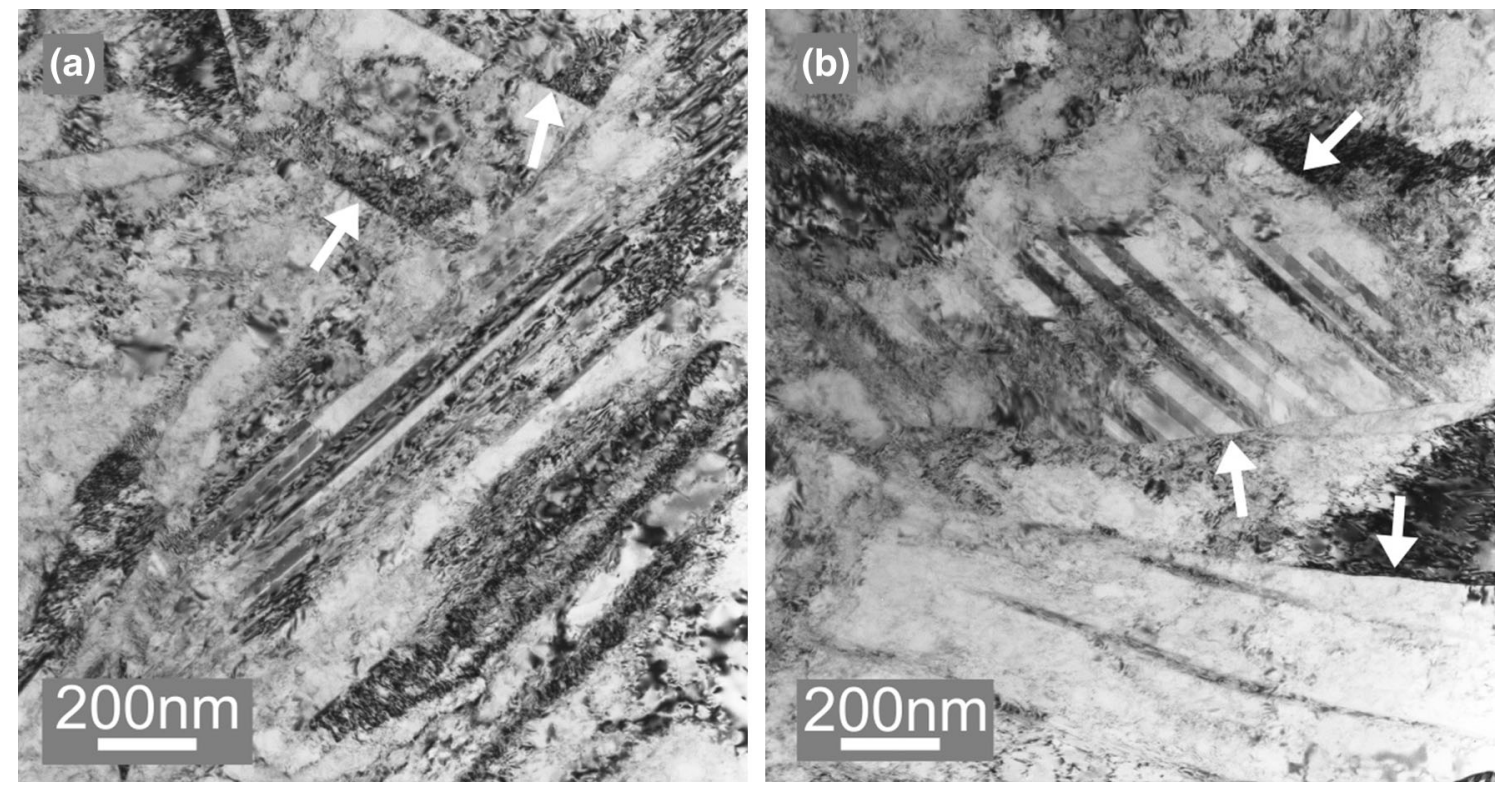

Fig. 9 Fine twinning is present in the gage section of the tensile specimen tested at room temperature. The twinning width/spacing often being in the $50 \mathrm{~nm}$ range. There is some indication of a grain size of a few hundred $\mathrm{nm}$, with several probable grain boundaries arrowed 

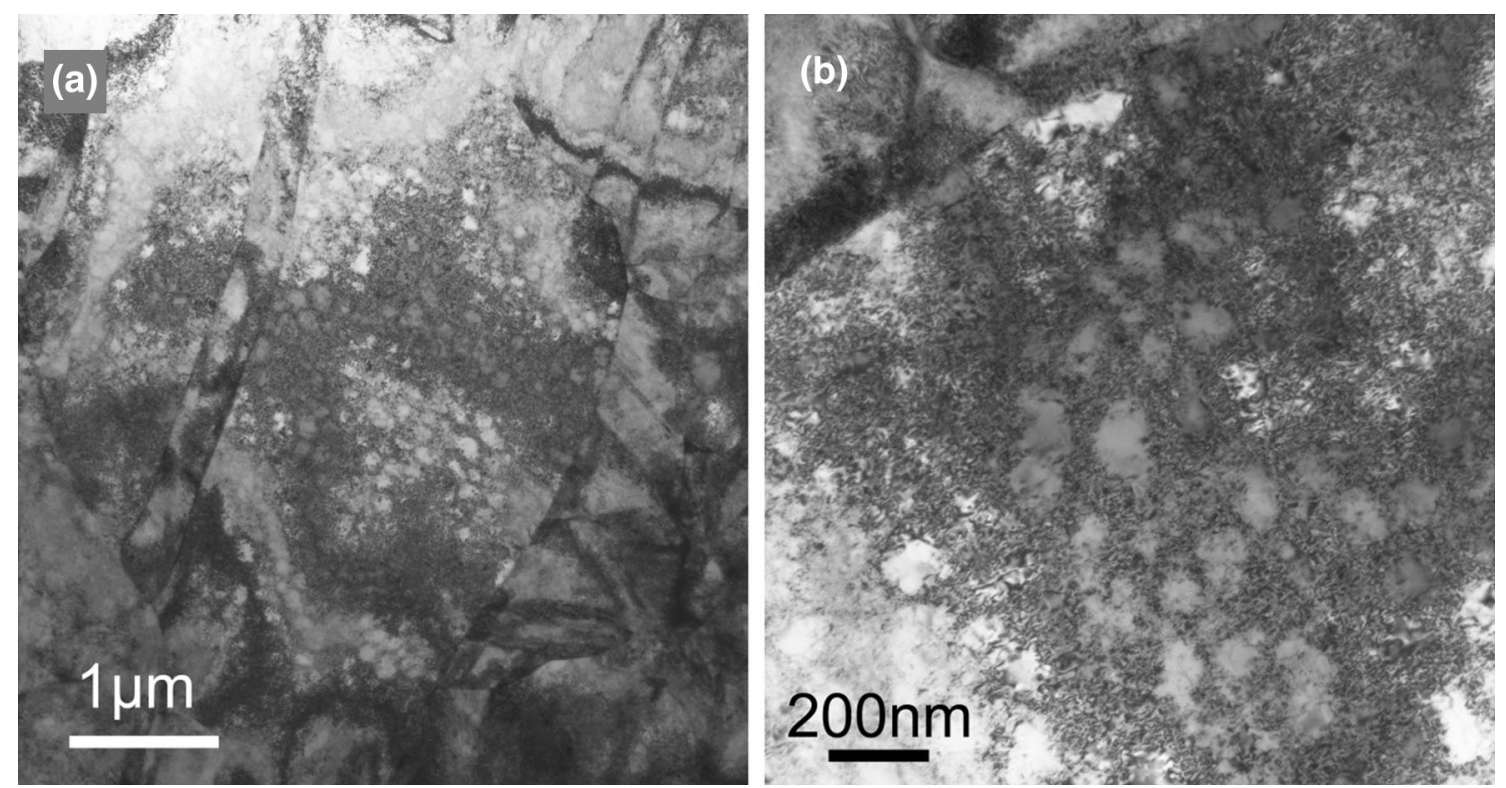

Fig. 10 Relatively structure-free zones were fairly common throughout the sample, although they were not necessarily uniformly distributed. There is no strong evidence that this anomalous contrast is related to alloy chemistry as XEDS showed no chemistry variation. Presumably, then, this structural feature arises from the deformation process which is enhanced due to preferential thinning during the electropolishing process

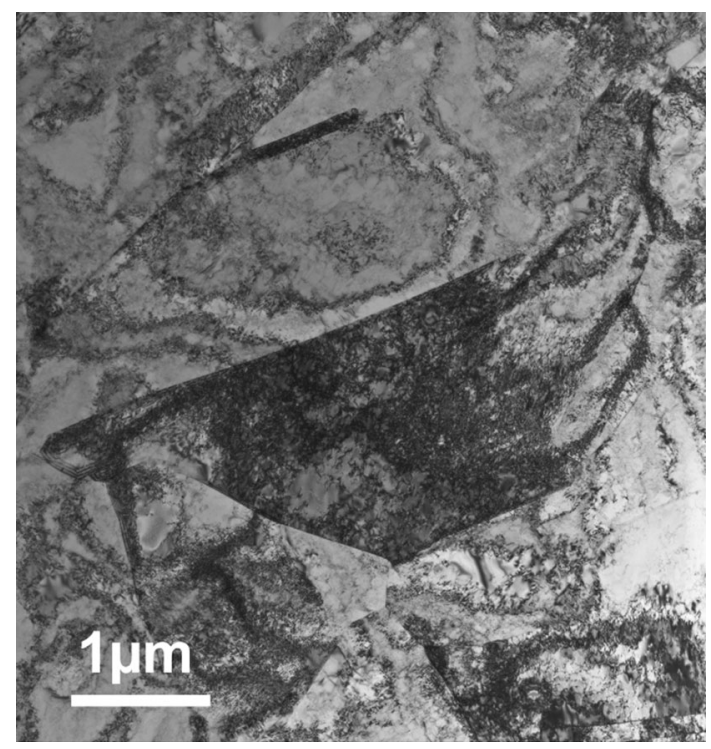

Fig. 11 As in the room temperature tested tensile specimen, the grain boundaries and twins are not readily discerned. Only some of the boundaries show clearly and only at selected tilt conditions. However, this image gives an indication of grain size, assuming the grain's obvious boundaries are high-angle boundaries, and not twin interfaces. Here, the grain size is seen to be roughly $1 \mu \mathrm{m}$ in width/diameter

observed is larger (i.e., mainly the width of the twin) while the frequency of twins is much less (i.e., a decrease in the number). Some twinning is apparent in the figure but is more clearly observed in Fig. 12.

Several structural features are seen in Fig. 12. There are numerous twins seen throughout the image, but note those to the left of the figure. At this magnification, many of the twins have widths at least $100 \mathrm{~nm}$ in size. At room temperature, clusters of the twins had widths in the 20 to $50 \mathrm{~nm}$ range. Also,

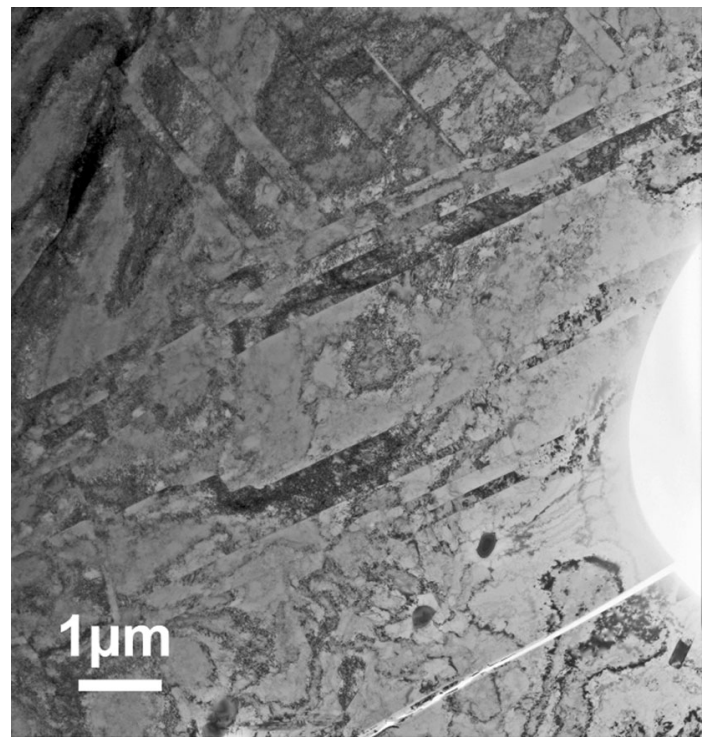

Fig. 12 Low magnification image of HEA1 tested at $500{ }^{\circ} \mathrm{C}$. Some of the boundaries show clearly, but only at selected tilt conditions. Note the twins in this micrograph. In addition to the grain size being larger for this specimen, the twins also appear larger

note the dark "spots" to the right. Upon detailed inspection, these spots were actually $\mathrm{Cr}$-rich precipitates with carbon also found in the XEDS spectra. At this juncture, they were assumed to be carbides. (Note from Table 1 that HEA1 had approximately 0.04 wt. $\%$ carbon.)

Not surprisingly, HEA1, i.e., $500{ }^{\circ} \mathrm{C}$ tensile-tested sample, exhibits a microstructure that includes some components of the room temperature tested samples. There is twinning, but not so much fine twinning as was seen in the room temperature sample. There is a high dislocation content, showing the same cellular type structure around dislocation-free regions as was 
observed in the room temperature sample. Some fine structures, believed to be micro-twins, were also observed (again, similar to the room temperature sample). These fine structures do not appear to be an additional phase as there was no XEDS or diffraction evidence. Weak beam, dark-field (WBDF) imaging was attempted, although working at preferred systematic diffraction conditions was out of the question due to the grain size, twinning, dislocation strain effects, etc. The empirical WBDF images that include bright contrast for dislocations against a dark background for the matrix material also include numerous fringes. Hopefully, these are evidence of stacking faults associated with the dislocation structure, not just the result of a poorly selected (multi-beam) diffraction condition.

The main difference between microstructures at room temperature and $500{ }^{\circ} \mathrm{C}$ and those after testing at $800{ }^{\circ} \mathrm{C}$ was the absence of dislocations. The pair of images shown in Fig. 13 shows this very clearly. While dislocations are clearly seen (at a density that reduces greatly the strain effects within the surrounding matrix), they are more typical of images in the literature for FCC materials. The left microstructure shows a single grain as the main feature with a particle inside the grain. There are bands of dislocations that traverse the grain from left
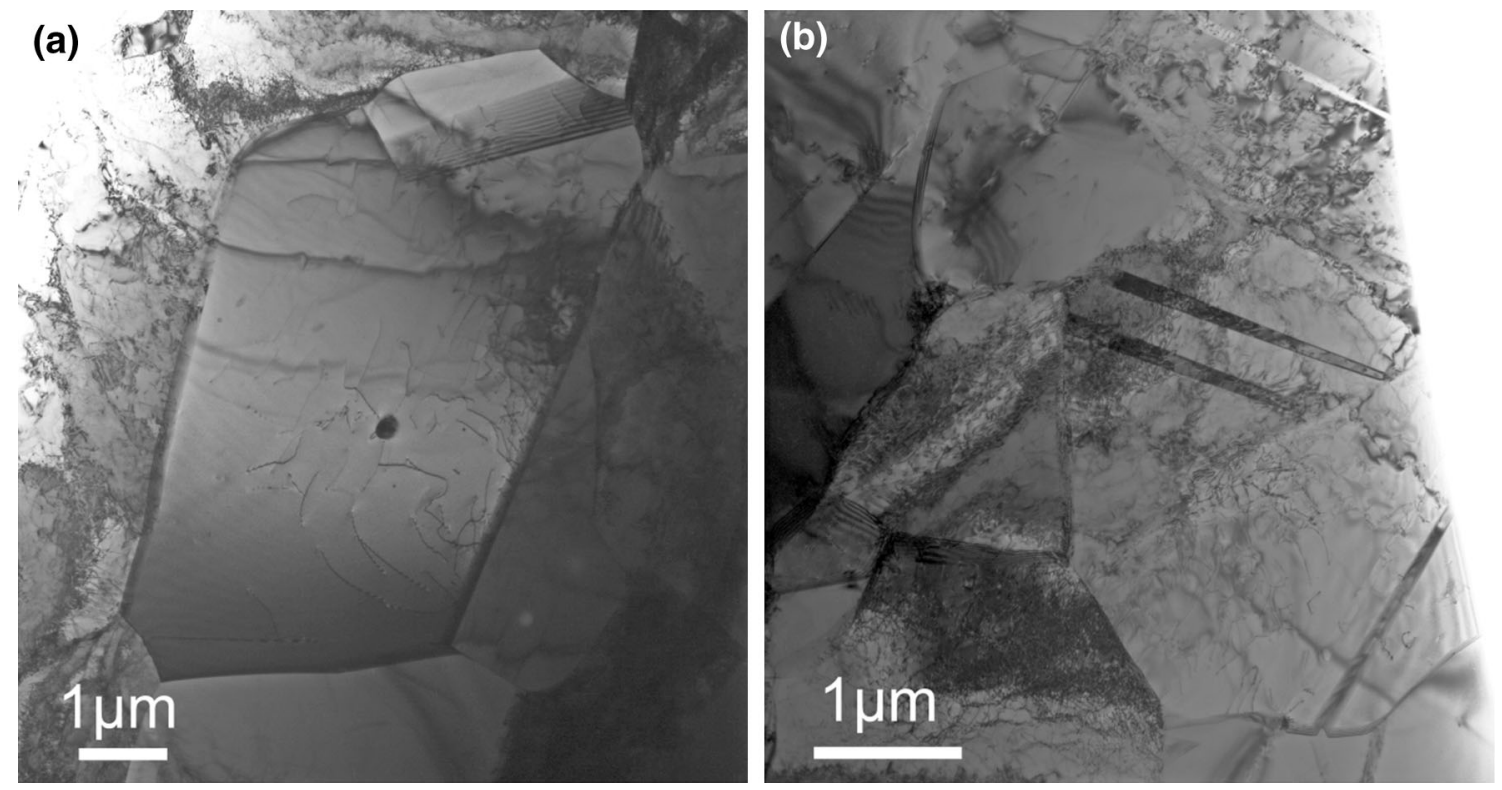

Fig. 13 General overview images, at non-specific orientations, with some fairly fine twinning (but not as fine, and not as 'jumbled' as in the room temperature tensile-tested sample)

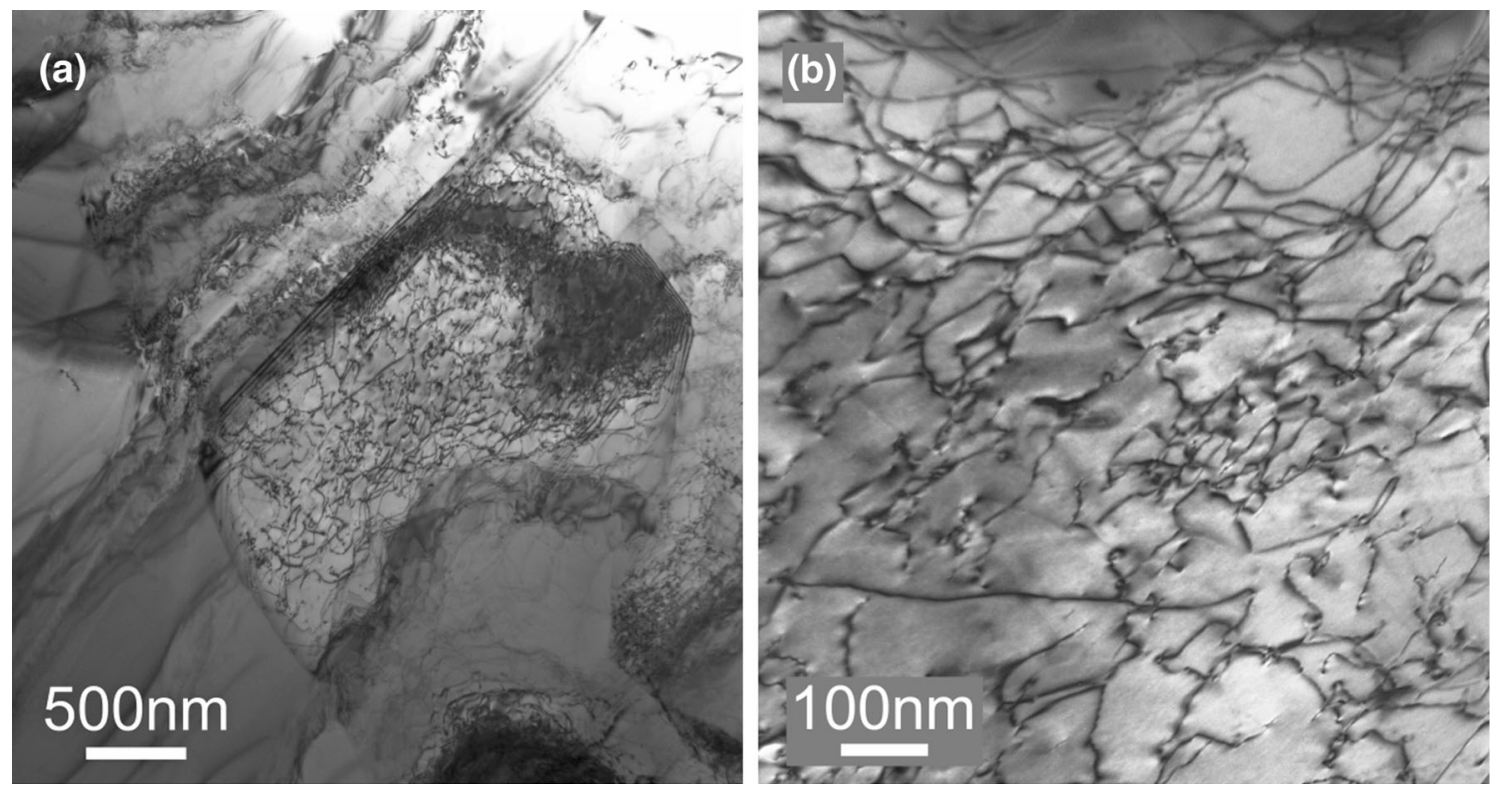

Fig. 14 Dislocations, imaged with a 111 reflection near a $\langle 110\rangle$ zone axis. The higher magnification image, at right, is from the center of the left image (and includes about $135^{\circ}$ of rotation) 
to right. High-angle boundaries are clearly seen. The micrograph on the right shows the same general features but with the addition of twins (other microscopy that is not presented here supports these observations, especially the bands of dislocations and the twinning).

For the bands of dislocations, it is hard to determine if they are entirely due to tensile deformation or have begun to reorganize into a lower energy structure (e.g., a subgrain boundary) due to the test temperature and duration of the tensile test at $800{ }^{\circ} \mathrm{C}$. Other images showed nice dislocation structures that could be due to either.

Alternatively, Fig. 14 shows a region of high dislocation density (for this specimen that is). In the micrograph on the left, the grain in the middle shows this clearly. Other regions to the upper left and lower right also show dense regions of dislocation arrangement reminiscent of low-angle boundaries. The micrograph on the right shows an image taken with the 111 reflection near a $\langle 110\rangle$ zone axis. This higher magnification photo allows the individual dislocations to be clearly imaged, showing the tortured nature of their interaction due to tensile deformation

Compared to the HEA-1 sample that was tensile tested at room temperature, this sample exhibits considerably less fine twinning. However, some twinning is present. Grain boundaries are much more readily observed and a few $\mathrm{Cr}$-rich precipitates (probably carbide) were found. The dislocation density was quite high across most of the sampled area, although a few grains were observed that appeared to be anomalously low in this regard, showing very few dislocations despite tilting through a fairly wide range of orientations. There is some evidence for deformation bands. Dislocations were resolved relatively easily (whereas with the room temperature and $500{ }^{\circ} \mathrm{C}$ samples, dislocations were unresolved due to their extremely high density and associated strain fields). Part of the reason for this is the test temperature which allows greater dislocation mobility, not only glide but climb. At least for HEA1, the test duration at $800{ }^{\circ} \mathrm{C}$ was much longer than at $500{ }^{\circ} \mathrm{C}$. (Note from Table 3 that elongation at $800{ }^{\circ} \mathrm{C}$ was $64 \%$ compared to $26 \%$ at $500{ }^{\circ} \mathrm{C}$, resulting in a longer time at a higher temperature for HEA1. Although TEM of HEA2 has not been completed, it is expected that for tests through $500{ }^{\circ} \mathrm{C}$ feature development will be much the same. Given the shorter duration test at $800{ }^{\circ} \mathrm{C}$ for HEA2, much of what has been seen in HEA1 at $800{ }^{\circ} \mathrm{C}$ may not occur to the same extent as in HEA2.)

\section{Conclusions}

In this preliminary examination of HEA alloys \#1 and \#2, the following conclusions were reached based on testing and microstructural inspection:

- Tramp contaminant elements such as O, N, C, and S were observed to come from high purity but conventional quality feed stocks. These impurities formed various precipitate phases including suspected $\mathrm{Mn}-\mathrm{S}$, Cr-based carbides, and oxides of $\mathrm{Al}$ and $\mathrm{Si}$.

- Grain refinement of both alloys was successful due to combined thermo-mechanical processing, i.e., hot forging followed by hot rolling.

- Previous efforts on HEA alloys do not specify or validate the level of homogenization in the HEA (Ref 20-25). This work differs in that it presents a validation of a homogenization treatment that reduced segregation to $1 \%$ of nominal chemistry for each element through the use of a computationally based algorithm (Ref 15).

- The microstructures of HEA1 and HEA2 are single phase with precipitates due to impurities from the starting feed stock. However, with the exception of second phases formed by the impurity elements, no second phases (other than these) were observed even at the TEM level.

- The general characteristics of tensile mechanical behavior are similar to that of 300-series austenitic stainless steels, in that these alloys (i.e., single-phase FCC matrix) undergo extensive work hardening during tensile deformation. The yield stress and tensile strength of HEA1 and HEA2 are, in general, consistent with what others have observed for these HEA compositions (Ref 22-25). More importantly, the HEAs studied herein tend to have tensile strength equivalent to, or greater than, typical of 300-series austenitic stainless steels. HEA1 and HEA2 also have higher yield stress than does $316 \mathrm{SS}$ but this may be a result of thermo-mechanical processing approach. As a consequence, the ductility is lower. Also, there is a decrease in ductility to a minimum for these HEAs, which while similar, for example, to $316 \mathrm{SS}$ is a bit deeper and occurs at higher temperatures.

- Serrated flow (Portevin-Le Chatelier effect) was observed in both HEA1 and HEA2 at $500{ }^{\circ} \mathrm{C}$. This behavior has been seen by others researching HEAs (Ref 30).

The main goal of this research was to produce single-phase HEAs using more commercial type melting practice. This has been accomplished. However, significant problems remain when considering other possible HEA combinations where differences in the melting range of the elements might prove challenging using large-scale commercial melting technologies.

Another significant problem in HEA manufacture has centered upon eliminating segregation in the consolidated alloy. This is more problematic in that segregation mainly arises from the way in which the material is produced (i.e., the meltsolidification route), and as such, such melting practice may limit the extent to which the residual segregation can be reduced. Significant segregation with associated phase formation can complicate material characterization and interpretation of mechanical properties (with reproducibility of microstructures also a problem).

\section{Acknowledgments}

This work was funded by the Cross-Cutting Technologies Program at the National Energy Technology Laboratory (NETL)-Strategic Center for Coal, managed by Robert Romanosky (Technology Manager) and Charles Miller (Technology Monitor). The Research was executed through NETL's Office of Research and Development's Innovative Process Technologies (IPT) Field Work Proposal.

\section{Disclaimer}

This report was prepared as an account of work sponsored by an agency of the United States Government. Neither the United States Government nor any agency thereof, nor any of their employees, 
makes any warranty, express or implied, or assumes any legal liability or responsibility for the accuracy, completeness, or usefulness of any information, apparatus, product, or process disclosed, or represents that its use would not infringe privately owned rights. Reference herein to any specific commercial product, process, or service by trade name, trademark, manufacturer, or otherwise does not necessarily constitute or imply its endorsement, recommendation, or favoring by the United States Government or any agency thereof. The views and opinions of authors expressed herein do not necessarily state or reflect those of the United States Government or any agency thereof.

\section{References}

1. M.-H. Tsai and J.-W. Yeh, High-Entropy Alloys: A Critical Review, Mater. Res. Lett., 2014, 2, p 107-123

2. K.H. Huang and J-W. Yeh, A Study on Multicomponent Alloy Systems Containing Equal-Mole Elements, M.S. Thesis, National Tsing Hua University, Hsinchu City, Taiwan, 1996

3. J.-W. Yeh, S.K. Chen, S.J. Lin, J.Y. Gan, T.S. Chin, T.T. Shun, C.H. Tsau, and S.Y. Chang, Nanostructured High-Entropy Alloys with Multiple Principal Elements: Novel Alloy Design Concepts and Outcomes, Adv. Eng. Mater., 2004, 6, p 299-303

4. Y. Zhang, T.T. Zuo, Z. Tang, M.C. Gao, K.A. Dahmen, P.K. Liaw, and Z.P. Lu, Microstructures and Properties of High-Entropy Alloys, Prog. Mater. Sci., 2014, 61, p 1-93

5. Y.-F. Kao, T.-J. Chen, S.-K. Chen, and J.-W. Yeh, Microstructure and Mechanical Property of As-Cast, -Homogenized, and -Deformed $\mathrm{Al}_{\mathrm{x}} \mathrm{CoCrFeNi}(0 \leq \mathrm{x} \leq 2)$ High-Entropy Alloys, J. Alloys Compd., 2009, 488, p 57-64

6. K.B. Zhang, Z.Y. Fu, J.Y. Zhang, J. Shi, W.M. Wang, H. Wang, Y.C Wang, and Q.J. Zhang, Annealing on the Structure and Properties Evolution of the CoCrFeNiCuAl High-Entropy Alloy, J. Alloys Compd., 2010, 502, p 295-299

7. K. Zhang and Z. Fu, Effects of Annealing Treatment on Phase Composition and Microstructure of $\mathrm{CoCrFeNiTiAl}_{\mathrm{x}}$ High-Entropy Alloys, Intermetallics, 2012, 22, p 24-32

8. C. Ng, S. Guo, J. Luan, S. Shi, and C.T. Liu, Entropy-Driven Phase Stability and Slow Diffusion Kinetics in an $\mathrm{Al}_{0.5} \mathrm{CoCrCuFeNi}$ High Entropy Alloy, Intermetallics, 2012, 31, p 165-172

9. O.N. Senkov, G.B. Wilks, D.B. Miracle, C.P. Chuang, and P.K. Liaw, Refractory High-Entropy Alloys, Intermetallics, 2010, 18, p 17581765

10. F. Otto, A. Dlouhý, C. Somsen, H. Bei, G. Eggeler, and E.P. George, The Influences of Temperature and Microstructure on the Tensile properties of a CoCrFeMnNi High-Entropy Alloy, Acta Mater., 2013, 61, p 5743-5755

11. F. Otto, N.L. Hanold, and E.P. George, Microstructural Evolution After Thermomechanical Processing in an Equiatomic, Single-phase CoCrFeMnNi High-Entropy Alloy with Special Focus on Twin Boundaries, Intermetallics, 2014, 54, p 39-48

12. B. Cantor, I.T.H. Chang, P. Knight, and A.J.B. Vincent, Microstructural Development in Equiatomic Multicomponent Alloys, Mater. Sci. Eng. $A, 2004, \mathbf{3 7 5}, \mathrm{p} 213-218$
13. F. Otto, Y. Yang, H. Bei, and E.P. George, Relative Effects of Enthalpy and Entropy on the Phase Stability of Equiatomic High-Entropy Alloys, Acta Mater., 2013, 61, p 2628-2638

14. P.D. Jablonski, J.J. Licavoli, M.C. Gao, and J.A. Hawk, Manufacturing High Entropy Alloys, JOM, 2015, 67, p 1-10. doi:10.1007/ s11837-015-1540-3

15. P.D. Jablonski and C.J. Cowen, Homogenizing a Nickel-Based Superalloy: Thermodynamic and Kinetic Simulation and Experimental Results, Metall. Mater. Trans. B, 2009, 40, p 182-186

16. ASTM Standard E8/E8M-15a: Standard Test Methods for Tension Testing of Metallic Materials, ASTM international, West Conshohocken, PA, 2015

17. M.F. Ashby, Fracture Mechanisms in Simple Tension, Progress in Materials Science, Chalmers Anniversary Volume, J.W. Christian, P. Haasen, and T.B. Massalski, eds., Pergamon Press, Oxford, NY 1981, p 1-25

18. B. Dodd and Y. Bae, Ductile Fracture and Ductility with Applications to Metalworking, Academic Press Inc, London, 1987, p 73-96

19. P.D. Jablonski and J.A. Hawk, The Practical Application of Minor Element Control in Small Scale Melts, in Proceedings of the 2013 International Symposium on Liquid Metal Processing and Casting, M.J.M. Krane, A. Jardy, R.L. Williamson, and J.J. Beaman, eds., Wiley, Hoboken, NJ 2013, p 329-332

20. C. Zhu, Z.P. Lu, and T.G. Nieh, Incipient Plasticity and Dislocation Nucleation of FeCoCrNiMn High-Entropy Alloys, Acta Mater, 2013, 61, p 2993-3001

21. B. Schuh, F. Mendez-Martin, B. Volker, E.P. George, H. Clemens, R. Pippan, and A. Hohenwarter, Mechanical Properties, Microstructure and Thermal Stability of a Nanocrystalline CoCrFeMnNi High-Entropy Alloy After Severe Plastic Deformation, Acta Mater., 2015, 96, p 258-268

22. A. Gali and E.P. George, Tensile Properties of High- and MediumEntropy Alloys, Intermetallics, 2013, 39, p 74-78

23. J.Y. He, C. Zhu, D.Q. Zhou, W.H. Liu, T.G. Nieh, and Z.P. Lu, Steady State Flow of the FeCoNiCrMn High Entropy Alloy at Elevated Temperatures, Intermetallics, 2014, 55, p 9-14

24. N.D. Stepanov, D.G. Shaysultanov, NYu Yurchenko, S.V. Zherebtsov, A.N. Ladygin, G.A. Salishchev, and M.A. Tikhonovsky, High Temperature Deformation Behavior and Dynamic Recrystallization in CoCrFeNiMn High Entropy Alloy, Mater. Sci. Eng. A, 2015, 636, p $188-195$

25. A.J. Zaddach, R.O. Scattergood, and C.C. Koch, Tensile Properties of Low-Stacking Fault Energy High-Entropy Alloys, Mater. Sci. Eng. A, 2015, 636, p 373-378

26. NIMS Creep Data Sheet 14B, National Institute for Materials Science, Japan, 1988

27. H. Aboulfadl, J. Deges, P. Choi, and D. Raabe, Dynamic Strain Aging Studied at the Atomic Scale, Acta Mater., 2015, 86, p 34-42

28. S.-G. Hong and S.-B. Lee, Mechanism of Dynamic Strain Aging and Characterization of Its Effect on the Low-Cycle Fatigue Behavior in Type 316L Stainless Steel, J. Nucl. Mater, 2005, 340, p 307-314

29. B. Swaminathan, W. Abuzaid, H. Sehitoglu, and J. Lambros, Investigation Using Digital Image Correlation of Portevin-Le Chatelier Effect in Hastelloy X Under Thermo-Mechanical Loading, Int. J. Plast., 2015, 64, p 177-192

30. J. Antonaglia, X. Xie, Z. Tang, C.-W. Tsai, J.W. Qiao, Y. Zhang, M.O. Laktionova, E.D. Tabachnikova, J.W. Yeh, O.N. Senkov, M.C. Gao, J.T. Uhl, P.K. Liaw, and K.A. Dahmen, Temperature Effects on Deformation and Serration Behavior on High-Entropy Alloys (HEAs), JOM, 2014, 66(10), p 2002-2008 